\title{
Usability of eHealth and Mobile Health Interventions by Young People Living With Juvenile Idiopathic Arthritis: Systematic Review
}

Sonia Butler ${ }^{1 *}$, BN (Hons), MEd, GradCertTeriaryEd; Dean Sculley ${ }^{1 *}, \mathrm{BSc}$ (Hons), MSc, PhD; Derek Santos Santos ${ }^{2^{*}}$, BSc (Hons), MSc, PhD; Antoni Fellas ${ }^{3 *}$, BHSc (Hons); Xavier Gironès ${ }^{4 *}, \mathrm{PhD}$; Davinder Singh-Grewal ${ }^{5,67,8^{*}}$, MBBS, MMedSci, PhD, FRACP; Andrea Coda ${ }^{3 *}$, BSc (Hons), PhD

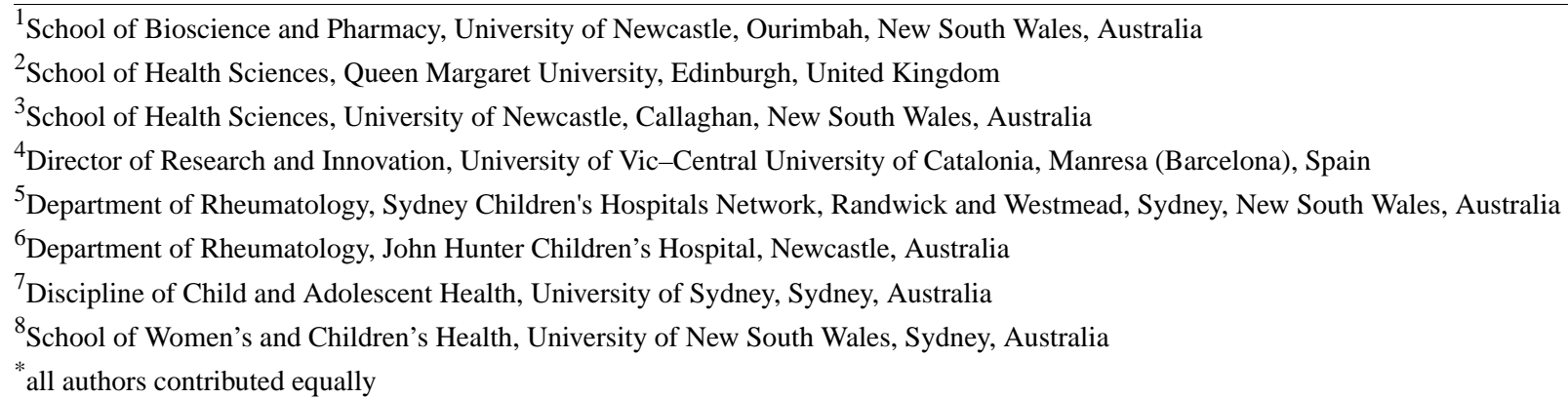

\section{Corresponding Author:}

Sonia Butler, BN (Hons), MEd, GradCertTeriaryEd

School of Bioscience and Pharmacy

University of Newcastle

10 Chittaway Rd

Ourimbah, New South Wales, 2258

Australia

Phone: 61421945914

Email: sonia.butler@newcastle.edu.au

\section{Abstract}

Background: Considering the changing landscape of internet use and rising ownership of digital technology by young people, new methods could be considered to improve the current model of juvenile idiopathic arthritis (JIA) management.

Objective: This systematic review aims to evaluate the usability of eHealth and mobile health (mHealth) interventions currently available for young people living with JIA.

Methods: The PRISMA (Preferred Reporting Items for Systematic Reviews and Meta-Analyses) guidelines were used to oversee this review. We systematically searched 15 databases for 252 potential studies; 2 authors independently screened all quantitative studies reporting the use of eHealth and mHealth interventions for young people (aged 1-18 years) diagnosed with JIA. Studies were excluded if they did not report outcome measures or were reviews, commentaries, or qualitative studies. Study methodological quality was scored using the Down and Black (modified) checklist. A narrative descriptive methodology was used to quantify the data because of heterogeneity across the studies.

Results: A total of 11 studies were included in this review, reporting 7 eHealth and mHealth interventions for young people (aged 4-18 years) living with JIA, targeting health issues such as pain, health-related quality of life, physical activity, and chronic disease self-management. The usability of the interventions was facilitated through training and ongoing support. The engagement was promoted by a combination of persuasive influences, and barriers preventing adherence were removed through personal reminders and flexible program schedules to cater to JIA and non-JIA illnesses or other commonly seen activities in childhood. The feedback obtained was that most young people and their parents liked the interventions.

Conclusions: The results of this review need to be considered cautiously because of the lack of rigorous testing and heterogeneity, which limits the detailed descriptions of data synthesis. Further research is needed to consider gender differences, associated costs, and the effectiveness of the interventions on health outcomes to better support young people living with JIA.

(JMIR Pediatr Parent 2020;3(2):e15833) doi: 10.2196/15833 


\section{KEYWORDS}

juvenile idiopathic arthritis; child; adolescence; eHealth; mHealth; systematic review; mobile phone; pain; physical activity; self-management; quality of life

\section{Introduction}

\section{Background}

Juvenile idiopathic arthritis (JIA) is the most common type of arthritis in young people $[1,2]$ with an incidence rate of 1.6 to 42.5 per 100,000, varying across different geographical locations and ethnic groups [3-6]. Symptoms include an unpredictable trajectory of joint inflammation [7], stiffness [8], pain [9], and fatigue [10] that can persist into adulthood. The active disease can impair functional ability [11,12], school attendance [13], and sleep [14], increasing the risk of poor psychosocial health [13], social isolation, reduced exam performance [15] and career prospects [16], affecting the quality of life [10,17,18]. At present, there is no definitive cure; instead, the current best practice supports timely interventions customized to manage inflammation, thus controlling pain, improving quality of life, and preventing long-term disability $[18,19]$.

\section{Improving the JIA Model of Care}

Responding to the needs of young people living with JIA is a challenge because of the problems in the current model of care $[19,20]$. A worldwide shortage of pediatric rheumatologists (PR) has limited most pediatric rheumatology services to tertiary children's hospitals, typically based in major capital cities. Services are also based on a retrospective method of health care delivery, where appointments are made 3 to 6 months in advance, which is slow to react to a patient's changing conditions [20-25].

Feedback from parent and carer surveys also suggests that pediatric rheumatology services need to improve the quality of their service and the patients' experience. Responses suggest they need to optimize their efficiency, improve information exchange $[26,27]$, promote ongoing interdisciplinary support networks [26-28], and improve access to a JIA experienced clinician when needing urgent advice [27] or experiencing an unpredictable flare of disease, complications, adverse reactions [26], or illness [28].

\section{Improving Self-Management Behavior}

Good self-management behavior has a positive effect on health outcomes [29]. Young people with JIA and their families need to be encouraged to take an active role in their disease management [30] and be provided with meaningful opportunities to develop the skills they need to support self-management [29]. This is important because young people do not automatically develop these skills [31], and they are not overly concerned about their long-term health outcomes. Instead, they are more concerned with the present [32], making disease management secondary to their school and social activities [33].

\section{Digital Solutions}

An innovative way to improve the current care model and foster self-management skills could be through eHealth or mobile health (mHealth) interventions [34-36], in particular, when considering the changing landscape of internet usage [37] and rising ownership of digital technology by young people [38] A growing generation of digital natives is inadvertently turning to digital solutions to support their daily lives [34,39]. From a young person's viewpoint, digital technology can promote a better understanding of their disease, support self-management, and remove the need for constant supervision by parents and clinicians [36]. From a clinician's perspective, digital technology can facilitate health promotion and allow real-time symptom monitoring $[34,36]$, potentially enabling timely changes to treatments and the prevention of flare-ups, thereby improving health outcomes and decreasing health care costs.

Critical to the success of any digital intervention is the manner in which young people accept and interact with the technology $[38,40,41]$. This understanding is often uncovered in usability testing. In recent years, usability testing has shifted from traditional technology testing to understanding and optimizing the users' experience [41-43] because user feedback can be different from the planned use of the intervention [43]. Usability testing that pursues a user-led design [35,41], particularly for specific populations, uncovers problems related to acceptability, perceived level of usefulness, and adherence. Aiding the delivery, uptake, and retention of an accessible intervention that fits into a young person's lifestyle and meets the needs of a wide and diverse range of users [44-47].

\section{Definition of eHealth and mHealth}

eHealth is described by the World Health Organization (WHO) as an activity that delivers health-related information, resources, and services through electronic technology and internet connectivity [48]. mHealth is described as a mobile and wireless form of technology for medical and public health practices [41].

\section{Aim and Rationale}

This systematic review presents the first of 2 steps in evaluating the clinical use of eHealth and mHealth interventions for young people (aged 1-18 years) living with JIA. This review aims to evaluate quantitative studies examining the usability of eHealth and mHealth interventions to understand how young people interact with the technology. The following 3 areas were considered:

1. Identification of the digital health intervention.

2. Usability (delivery of the intervention) $[47,48]$.

3. Costs associated with the intervention [48].

It is anticipated that such information will improve our understanding of the mechanisms that support the use of these interventions by young people living with JIA and inform future development. The second step of this review aims to evaluate the effectiveness of interventions. These results will be published subsequently in another review. 


\section{Methods}

\section{Overview}

The PRISMA (Preferred Reporting Items for Systematic Reviews and Meta-Analyses) statement [49] guided this review (Multimedia Appendix 1). The protocol for this systematic review was registered on PROSPERO (International Prospective Register of Systematic Reviews; ID CRD42018108985) [50].

\section{Eligibility Criteria}

\section{Participants}

All young people (aged 1-18 years) diagnosed with JIA using the International League of Associations for Rheumatology criteria [51] were considered eligible.

\section{Interventions}

Any eHealth or mHealth interventions (see definition in the Introduction) delivered through an electronic device with internet connectivity [46] or wireless capacity were eligible [52].

\section{Comparator/Control}

No comparator was used.

\section{Outcomes}

We considered an outcome as any quantifiable measure specifically targeting the pediatric population or pediatric rheumatology.

\section{Study Design}

All quantitative studies reporting the use of eHealth and mHealth interventions for young people (aged 1-18 years) diagnosed with JIA were included. Studies were excluded if they did not report outcome measures or were reviews, commentaries, or qualitative studies.

\section{Search Strategy}

To develop search terms, MEDLINE and CINAHL were initially searched by SB to identify keywords in the titles, abstracts, and indexed terms. In October 2018, the search terms were adapted to suit the controlled vocabulary, Boolean operators, truncation, and wildcards in MEDLINE/PubMed, the Cochrane Library, Joanna Briggs Institute, AMED (Allied and Complementary Medicine Database), CINAHL complete, EMBASE, JAMA (Journal of the American Medical Association), Informit Health, ProQuest database, PsycINFO, IEEE (Institute of Electrical and Electronics Engineers and Institution of Engineering and Technology) Xplore, SAGE Publishing, ScienceDirect, Scopus, and Web of Science. Further studies were retrieved from Google Scholar and arthritis-related organizations (Arthritis Australia, Arthritis Foundation, and Childhood Arthritis and Rheumatology Research Alliance funded projects and conferences) and by hand searching reference lists. The search strategy was not restricted by language or year of publication. The database search was repeated in November 2019 (Multimedia Appendix 2).

\section{Study Selection}

Two authors (SB and AC) independently reviewed all studies retrieved by the search strategy via individual log-in systems on the web-based platform Covidence [53]. Titles and abstracts were reviewed against the inclusion and exclusion criteria and full-text versions. Authorship and results were not masked, and any disagreements were discussed and resolved by SB and AC. To gain access to all full-text studies, corresponding authors were contacted by email, or the full text was retrieved by the University of Newcastle library interlibrary request service Get It. There was no need for translation sources; only 1 study was retrieved in a language other than English (Dutch), and an English version of the same study was attained through ResearchGate.

\section{Data Collection}

A data extraction Excel (Microsoft) form was designed to collect all relevant information from the studies, including participant demographics, eHealth or mHealth characteristics, study design, study outcomes, and costs. Conclusions were drawn from the outcomes reported by study authors. Data extraction was completed by SB and checked by all reviewers.

\section{Risk of Bias}

Using the Down and Black (modified) checklist for randomized and nonrandomized studies [54,55], studies were rated independently by 2 reviewers (SB and AF). This checklist has a high correlation with similar tools for validity $(r=0.90)$ and reliability ( $r=0.69-0.90)$ [54,55]. The checklist considers 5 main assessment areas: (1) reporting; (2) external validity; (3) internal validity, bias; (4) internal validity, cofounding and selection bias; and (5) power; it provides an overall score out of 28 [56]. Across the studies, a disagreement rate of only $7.6 \%$ arose (13 of 170 questions), which was resolved through discussion (SB and $\mathrm{AF}$ ) and re-examination of the studies.

\section{Summary Measures}

To summarize the participants' characteristics, the mean scores reported by the study authors were averaged. The range of data was determined by the reported highest and lowest values. Individual JIA subtypes were combined and expressed as the total number (n) and the proportion of each subtype as a percentage $(\%)$. The total number of studies including the information required was stated (ie, "4 studies reported...") to account for missing data.

\section{Synthesis of Results}

Meta-analysis was considered unsuitable for this systematic review because of the heterogeneity across the studies and the different intervention development stages. Instead, a narrative synthesis methodology was used to allow the data to be organized, explored, and presented in a logical way [57] to uncover potential similarities and differences, associations, and patterns within the results $[57,58]$. The 4 stages of analysis suggested by Popay et al [58] were adapted and used to guide this review.

1. Develop a theoretical model to understand how the intervention works.

2. Conduct a preliminary synthesis to: 
- identify factors supporting implementation and barriers;

- consider relationships among studies.

3. Perform a content analysis (translation of data) to:

- $\quad$ report characteristics among studies;

- identify moderator variables;

- develop numerical/statistical rubrics.

4. Draw a conclusion by critically reflecting on methodology synthesis.

\section{Results}

\section{Study Selection Process}

A total of 252 studies were identified using the search strategy. After removing 70 duplicates, 127 studies that did not meet the inclusion criteria based on their title or abstract and 44 based on the full-text screening, a total of 11 studies met the inclusion criteria for this review (Figure 1).

Figure 1. Summary of the study selection process using the PRISMA (Preferred Reporting Items for Systematic Reviews and Meta-Analyses) diagram.
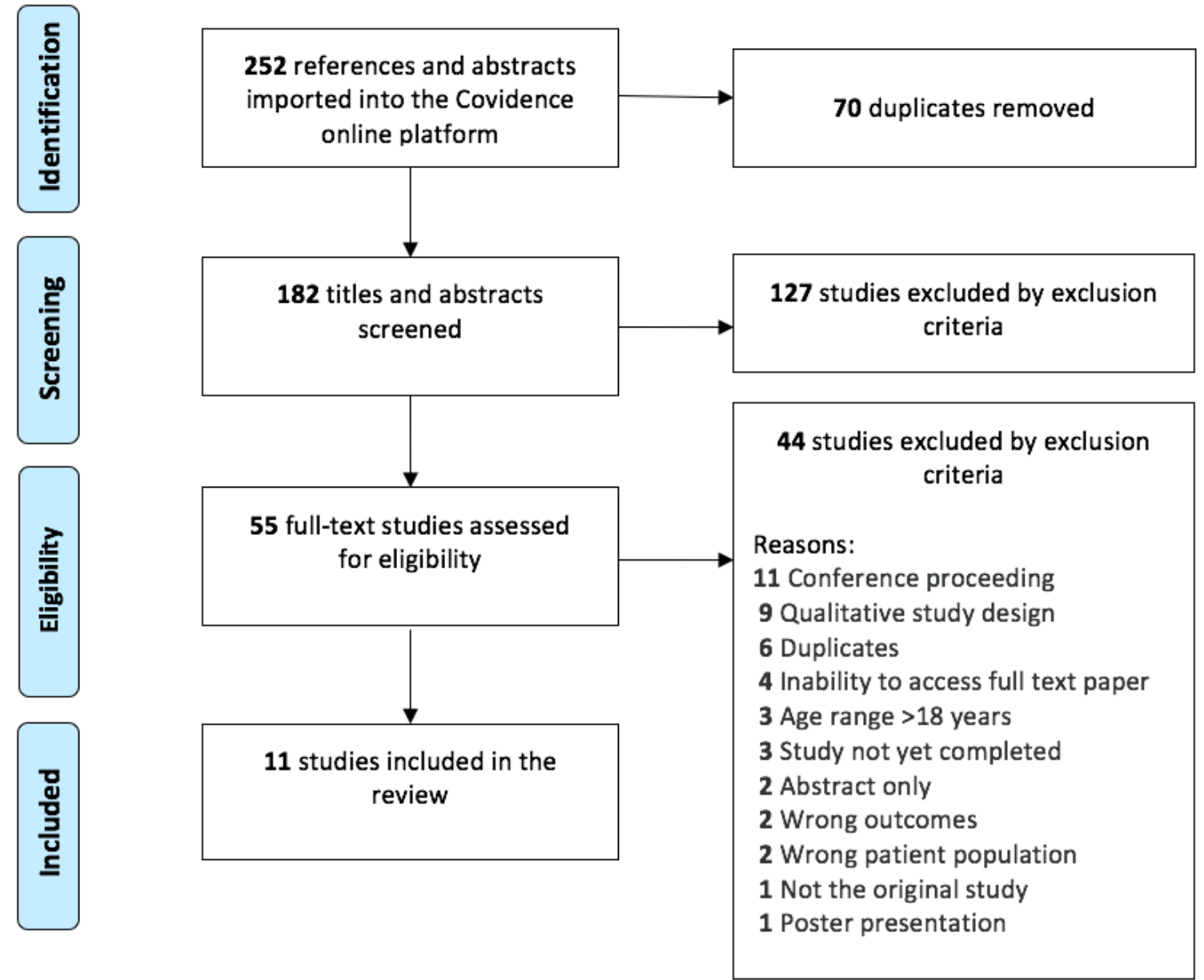

\section{Study Characteristics}

\section{Participants}

This review included 634 participants [59-67]; 57.1\% (362/634) of participants were recruited from either pediatric rheumatology departments or clinics affiliated to a hospital, and $42.9 \%$ (272/634) of participants from pediatric tertiary care centers. Study sample sizes ranged from 13 to 176 participants and varied in age (mean 12 years, SD 2.5; range 4-18.6 years), gender (female: $429 / 602,71.3 \%$; mean 42.9, SD 31.6), and JIA subtypes (Table 1) [59-67]. To avoid duplication, a total of 2 studies were excluded from this analysis $[68,69]$, because the participant characteristics were reported in another study included in this review [61,67]; furthermore, 3 studies did not report participants characteristics when participants were lost in follow-up $(32 / 634,5.0 \%)$, reducing the age and gender analysis to 602 of 634 participants $[60,61,63]$. 
Table 1. Juvenile idiopathic arthritis subtypes, based on the International League of Associations for Rheumatology criteria.

\begin{tabular}{|c|c|}
\hline Juvenile idiopathic arthritis subtypes & Value \\
\hline Oligoarthritis $^{\mathrm{a}}, \mathrm{n}(\%)$ & $195(30.8)$ \\
\hline Polyarthritis ${ }^{\mathrm{b}}, \mathrm{n}(\%)$ & $172(27.1)$ \\
\hline Polyarthritis (rheumatoid factor positive), n (\%) & $41(6)$ \\
\hline Enthesitis related, n (\%) & $54(8)$ \\
\hline Systemic, n (\%) & $46(7)$ \\
\hline Psoriatic, n (\%) & $33(5)$ \\
\hline Undifferentiated, n (\%) & $7(1)$ \\
\hline Unknown or not yet diagnosed or other, n (\%) & $39(6)$ \\
\hline Chronic arthritis with other/or other forms of rheumatic disease ${ }^{\mathrm{c}}, \mathrm{n}(\%)$ & $13(2)$ \\
\hline Not recorded, $\mathrm{n}(\%)^{\mathrm{d}}$ & $34(5)$ \\
\hline Disease activity $(\mathrm{cm})$, mean (range) ${ }^{\mathrm{e}}$ & $1.8(0.2-3.7)$ \\
\hline Disease duration, mean (range) ${ }^{\mathrm{f}}$ & 5 years $(<1$ month- 15.65 years $)$ \\
\hline
\end{tabular}

${ }^{\mathrm{a}}$ Includes the subcategories of oligoarthritis: persistent and extended [60,62-64,66].

${ }^{\mathrm{b}}$ Includes 2 studies not reporting positive or negative rheumatoid factor. [63,67].

${ }^{\mathrm{c} J u v e n i l e ~ d e r m a t o m y o s i t i s, ~ s y s t e m i c ~ l u p u s ~ e r y t h e m a t o s u s ~[62,63] . ~}$

${ }^{\mathrm{d}}$ Reasons: drop-out, loss of follow-up $(\mathrm{n}=32)$ [60,61,64] and missing subtypes $(\mathrm{n}=2)$ [64]

${ }^{\mathrm{e}} \mathrm{A}$ total of 8 studies reported disease activity [59,60,62,63,65-68].

${ }^{\mathrm{f}} \mathrm{A}$ total of 7 studies reported disease duration [60,62,64-68].

\section{Intervention}

The 11 studies included in this review reported 7 interventions, describing varying stages of development (preprototype to maturity); 4 interventions were web-based programs [61-65,68], 1 intervention was a computer-mediated electronic peer mentoring program (e-mentoring) [60], and 2 interventions used mobile technology for real-time monitoring [66,67,69]. The clinical significance of interventions aimed at improving self-management behavior [59-61,64,65,68] or supporting clinical decisions $[62,66,67,69]$. These interventions included the following:

1. Misfit Flash, a commercially available wearable tracker to improve physical activity [59].

2.Rheumates@Work, a web-based educational and cognitive behavioral program to improve self-management and physical activity $[61,64,68]$.

3. iPeer2Peer Program, an online peer mentoring program to facilitate positive role modeling and social support through video calls [60].

4. eOuch, a customized electronic pain diary to self-report real-time pain $[66,67,69]$.

5. ePROfile a web-based assessment (Kwaliteit van leven in kaart, or, quality of life map [KLIK] website) to self-report health-related quality of life (HRQoL) issues [62].
6. SUPER-KIDZ, a web-based pain assessment to self-report real-time pain [63].

7. Teens Taking Charge: Managing Arthritis Online, a web-based program to provide disease-specific information and self-management strategies [65].

Custom-designed programs designed by the research team were used in 5 interventions [61-69], and 2 interventions were commercially available $[59,60]$. The equipment necessary to operate these interventions included computers, laptops, handheld PDAs, an Apple iPod touch, and a wearable accelerometer synchronized to a smartphone. This allowed the interventions to be used at the participants' home [59-62,64-69] or clinic [62,63] (Multimedia Appendix 3).

\section{Outcomes}

Study outcomes considered feasibility, usability, efficiency, and/or effectiveness. To align usability outcomes with research questions 2 and 3, usability outcomes were synthesized to form 4 themes: (1) user engagement (promotional activities and adherence), (2) barriers preventing usability (personal, technical, and device barriers), (3) user feedback (acceptability and satisfaction), and (4) cost assessment (basic financial costs). Themes were based on 5 of 16 areas of reporting by Agarwal et al [41] to improve the quality of evidence being extracted. The remaining areas of reporting are beyond the scope of this review (Table 2). 
Table 2. Formation of themes, evaluation criteria, and main outcomes supporting the delivery of the eHealth and mobile health interventions for juvenile idiopathic arthritis.

\begin{tabular}{|c|c|c|c|c|c|c|c|c|c|}
\hline \multicolumn{3}{|c|}{ Research question, theme, and evaluation criteria } & \multicolumn{7}{|c|}{ Outcomes } \\
\hline \multicolumn{10}{|l|}{ Research question 2} \\
\hline \multicolumn{10}{|l|}{ User engagement } \\
\hline \multicolumn{3}{|l|}{ Promotional activities } & \multicolumn{7}{|c|}{ Adoption inputs [59-61,64-69] } \\
\hline \multicolumn{3}{|l|}{ Adherence } & \multicolumn{7}{|c|}{$\begin{array}{l}\text { Activity log, dropout [59] participation rate [68], program adherence [60,64], commitment, } \\
\text { level of interaction [61], program compliance }[65-67,69] \text {, and safety }[59,60,64]\end{array}$} \\
\hline \multicolumn{10}{|l|}{ Barriers preventing usability } \\
\hline \multicolumn{3}{|c|}{$\begin{array}{l}\text { Personal barriers, technical barriers, or device } \\
\text { barriers }\end{array}$} & \multicolumn{7}{|c|}{$\begin{array}{l}\text { Device malfunction rate [59], barriers preventing engagement [59], technical problems } \\
{[61,63,66] \text {, missed responses [63], or errors [67] }}\end{array}$} \\
\hline \multicolumn{10}{|c|}{ User feedback } \\
\hline Acceptability & \multicolumn{9}{|c|}{ Questionaries $[60,63,65]$ and evaluation questionnaire $[66,67]$} \\
\hline Satisfaction & & & \multicolumn{7}{|c|}{$\begin{array}{l}\text { Questionaries }[60-63,65] \text {, semistructured phone interview [60], and evaluation of use } \\
\text { [62] }\end{array}$} \\
\hline \multicolumn{10}{|l|}{ Research question 3} \\
\hline \multicolumn{10}{|l|}{ Cost assessment } \\
\hline \multicolumn{3}{|c|}{ Basic financial cost (owing to no comparator) } & \multicolumn{7}{|c|}{$\begin{array}{l}\text { Cost (adding together development of the program, staff costs, financial consequences } \\
\text { ie, traveling expenses and babysitters) [61] }\end{array}$} \\
\hline \multicolumn{5}{|c|}{$\begin{array}{l}\text { Study Design } \\
\text { The study design included } 4 \text { descriptive studies, } 3 \text { pilot } \\
\text { randomized controlled trials (RCTs), } 1 \text { multicenter RCT, } 1 \text { pre- } \\
\text { and postintervention design, } 1 \text { correlational research design, } \\
\text { and } 1 \text { sequential cohort study-studies reported from } 2 \\
\text { high-infrastructure countries, Canada }[59,60,63,65-67,69] \text { and } \\
\text { the Netherlands }[61,62,64,68] \text { (Multimedia Appendix 4). }\end{array}$} & $\begin{array}{l}\text { Parti } \\
\text { the } \\
\text { activ } \\
\text { avail } \\
\text { Mult } \\
\text { Res } \\
\text { The }\end{array}$ & $\begin{array}{l}\text { ants were s } \\
\text { ikelihood } \\
\text { owning a } \\
\text { lity of the } \\
\text { edia Appen } \\
\text { s of Studic } \\
\text { 1: User } E\end{array}$ & $\begin{array}{l}\text { ted acc } \\
\text { nedicati } \\
\text { nputer/t } \\
\text { ternet, } \\
5 . \\
\text { geliver } \\
\text { gemer }\end{array}$ & $\begin{array}{l}\text { g to dise } \\
\text { hanges, } \\
\text { /interactiv } \\
\text { literacy } \\
\text { the Inte }\end{array}$ & $\begin{array}{l}\text { activity, pain, } \\
1 \text { of physical } \\
\text { nobile phone, } \\
\text { els ([59-69]) } \\
\text { ntion }\end{array}$ \\
\hline \multicolumn{5}{|c|}{ Methodological Quality of Studies } & Pron & tional Activ & & & \\
\hline \multicolumn{5}{|c|}{$\begin{array}{l}\text { The methodological quality of study scores ranged from } 15 \text { to } \\
21 \text { out of } 28 \text { (mean score } 18.6, \text { SD } 1.9 \text { ), a fair to good score } \\
\text { [54]. Convenience sampling and/or selection bias meant that } \\
\text { study participants may not fully represent the JIA population. }\end{array}$} & $\begin{array}{l}\text { All } \\
\text { enga } \\
{[59-(} \\
\text { (Tab }\end{array}$ & $\begin{array}{l}\text { udies repo } \\
\text { ment with tl } \\
65 \text { ] and ong } \\
\text { 3). }\end{array}$ & $\begin{array}{l}\text { prom } \\
\text { atervent } \\
\text { g huma }\end{array}$ & $\begin{array}{l}\text { al activi } \\
\text { The top } 2 \\
\text { nmunicat }\end{array}$ & $\begin{array}{l}\text { to support } \\
\text { luded training } \\
{[60,61,64-66]}\end{array}$ \\
\hline Promotional activity & Misfit flash & Rheumat & s@Work & ePR & Ofile & iPeer2Peer & eOuch & $\begin{array}{l}\text { SUPER- } \\
\text { KIDZ }\end{array}$ & $\begin{array}{l}\text { Teens taking } \\
\text { charge }\end{array}$ \\
\hline Training & $Y^{\mathrm{a}}$ & $\mathrm{Y}$ & & $\mathrm{Y}$ & & $\mathrm{Y}$ & $\mathrm{Y}$ & $\mathrm{Y}$ & $\mathrm{Y}$ \\
\hline Instruction manual & $\mathrm{Y}$ & $-\mathrm{b}$ & & - & & - & $\mathrm{Y}$ & - & - \\
\hline Goals set by users & $\mathrm{Y}$ & Y & & - & & - & - & - & $\mathrm{Y}$ \\
\hline Ongoing technical support & - & $\mathrm{Y}$ & & - & & - & $\mathrm{Y}$ & - & $\mathrm{Y}$ \\
\hline Personal reminders & - & - & & - & & - & $\mathrm{Y}$ & - & - \\
\hline Ongoing human communication & - & Y & & - & & Y & $\mathrm{Y}$ & - & $\mathrm{Y}$ \\
\hline Reactive feedback loop & - & $\mathrm{Y}$ & & - & & - & & - & - \\
\hline Linear design & - & Y & & - & & - & $\mathrm{Y}$ & - & $\mathrm{Y}$ \\
\hline Interactive content & - & $\mathrm{Y}$ & & - & & - & & - & $\mathrm{Y}$ \\
\hline $\begin{array}{l}\text { Flexibility in length of the pro- } \\
\text { gram }\end{array}$ & - & Y & & - & & Y & & - & Y \\
\hline
\end{tabular}

${ }^{\mathrm{a}}$ Y: yes.

${ }^{\mathrm{b}}$ The promotional activity listed was not used. 


\section{Training}

All interventions provided participants and/or parents with training (range <5-20 min) [59-63]. Training sessions included how to use the software [69], functionality [59,69], demonstration and practice using pain vignettes [66,69], and instruction on completing learning modules and pain entries $[61,66] ; 3$ interventions also provided training for those supporting the intervention: PRs, peer mentors, and a coach $[60,62,65]$. One study reported flexibility in training, delivering training at the participant's home or clinic [67] (Multimedia Appendix 2).

\section{Ongoing Human Communication}

Throughout the study period, 4 interventions provided ongoing human communication $[60,61,64-66,68]$. Human communication included telephone support [60,61,64-66], emails [60,64,65], face-to-face group sessions [64,68], daily monitoring of discussion boards [60,65], peer support [60, 65], and an online chat room [61]. A good-quality study, Teens taking charge: managing arthritis online, considered the use of a coach, providing weekly telephone calls as a necessary part of the intervention, reporting 1.6 calls (mean duration $17.3 \mathrm{~min}$, range 7-30 min) each week for the intervention group (IG) [65]. After the study period, the control group (CG) was given access to the intervention, without the coach and telephone support. Website engagement dropped compared with the IG, from 436.9 to 6.42 hours. Similarly, interaction by parents of the CG reduced from 458 to 19 hits [65].

\section{Safety Support}

A total of 3 fair to good-quality studies monitored participants' safety $[59,60,64]$. The iPeer2Peer Program reported that all Skype calls were recorded and reviewed within 24 hours by a research team member. The peer mentor was also trained to flag concerns [60]. For Rheumates@Work, the PR maintained disease activity and medication usage records, reporting disease flare-ups for 3 participants (IG, $n=1 / 17$; $C G, n=2 / 16$ ), and no adverse events [64]. Misfit Flash, reported illness, injury, or pain for 9 participants due to being active $(n=9 / 28)$ and arthritis-related pain for 1 participant $(n=1 / 28)$. However, no significant difference was reported for pain, functionality, or disease activity during the study period [59].

\section{Adherence Rates}

All interventions had an expected level of engagement, ranging from minutes to 17 weeks [59,60,62-69]. A total of 8 fair to good-quality studies monitored adherence rates (range 70\%-82.1\%) [59-61,63-67,69]; 4 studies increased adherence by allowing more time to complete the intervention $[60,61,64,65]$, and 1 study increased adherence to $100 \%(n=46)$ [65] ([59-61,64-67,69] Multimedia Appendix 6).

\section{Week to Week and Time of Day Adherence}

A significant difference was seen in adherence in pain reporting, using the eOuch pain diary, by 2 fair to good quality studies, week to week and according to the time of day (Multimedia Appendix 6) [66,67]. Adherence rates were increased $10 \%$ across the day by adjusting the preset pain reporting reminder alarms (morning, on waking, after school, and evening, before bed) according to age, 1.5 hours later on weekend mornings for older participants and 30 min earlier in the evenings for younger participants [66].

\section{Gender and/or Age Adherence}

The impact of gender and/or age on adherence was considered by 2 high-quality studies $[60,67]$. eOuch $(\mathrm{n}=112)$ reported gender or age had no effect [67]. Conversely, the iPeer2Peer Program reported that male participants $(n=2 / 18)$ had lower adherence [60]. The 2 male participants completed 5 and 7 video calls, respectively, instead of the expected 10 as per protocol, and call length was nearly half that of female participants $(12 / 16)$ [60].

\section{Content Adherence}

The most common topics raised/learning modules visited by participants in self-management programs were reported by 3 high-quality studies. The most common were understanding arthritis and management issues [60,61,65] (Multimedia Appendix 6).

\section{Theme 2: Barriers Preventing Usability}

\section{Personal Barriers}

Personal barriers preventing adherence were reported qualitatively by 6 fair to good-quality studies. The main barrier was illness, both JIA- and non-JIA-related [59-61,65,68]. In the iPeer2Peer Program, illness affected both the participants and peer mentors [60]. Other barriers included hospitalization $[61,65]$, injury and pain [59], and common childhood activities such as study time/assessments [59,60,65,66,69], school trips [61], extracurricular activities [59], holidays [61,66], a party, a sports tournament [61], loss of mobile phone privileges, loss of activity tracker [59], death in the family, being too busy, weather, no babysitter for siblings [61], no longer interested $[61,68]$, and no specific reason $[61,64,68]$.

\section{Technical Barriers}

Technical barriers preventing adherence were reported by 7 fair to good-quality studies [59,61,63,65-67]. Barriers included log-in [61,65], software [59,66,67], hardware [59], device $[59,66]$, and network problems $[63,66,67]$. This resulted in participants dropping out of the study [65] and lost data $[63,67]$. Future problems were eliminated through software changes, consultation with network providers, instructions on how to reset the device [66], and data back-up [66,67] ([59,61,63,65-67,69] Multimedia Appendix 7).

\section{Device Barriers}

Overall, 3 fair to good-quality studies compared electronic eOuch pain diary entries $[66,67,69]$ with the paper-based pain assessment—brief pain inventory (BPI), short-form [70]. In 1 study, participants made no errors using eOuch compared with $90.8 \%$ (69/76) of errors using the BPI [67]. Most errors were related to how they marked the visual analog scale- $77 \%$ $(55 / 76)$ were confused by the order of least, average, and worst pain ratings. Participants with higher pain levels made more errors. There was no statistical difference in age $(P=.51)$ or sex $(P=.40)$ [67].

In another fair-quality study, 3 different devices were compared by children (aged 4-7 years), adolescents (aged 8-18 years), and 
parents when completing the web-based pain assessment SUPER-KIDZ [63]. These devices included paper, a handheld Apple iPod touch (second generation), and a computer/laptop. The study reported a significant difference in the number of missed responses by adolescents using the iPod $(P=.047)$ compared with parents $(P=.16)$ and children $(P=.37)$ [63]. The iPod also required the most amount of time for adolescents and parents $(P<.001)$, followed by computer $(P<.001)$ and paper $(P<.001)$. There was no significant difference in the device used by children completing a 2 -item survey $(P=.64)$ [63].

In the same study, children preferred the computer to paper or iPod because it was simple and fun to use $(P=.008)$ [63]. Adolescents least liked the iPod because of size, unfamiliarity, and increased time to complete responses $(P=.001)$. Adolescents also described paper assessments as the most inappropriate for their age group $(P=.004)$ [63].

\section{Theme 3: User Feedback}

\section{Acceptability and Satisfaction}

All 7 interventions gained positive feedback from young people [59-63,65-67]. A total of 8 fair to good-quality studies reported that young people liked being physically active [59], making new friends [61], meeting someone with JIA whom they could relate to, or who had already experienced what they were going through (JIA- and non-JIA related) [60], how the intervention looked [66,67], the intervention's content [65], getting information about JIA [60], personalization through interactive features [65], and an email character called Buddy [61]. Four studies reported that young people would continue to use or recommend interventions [59,65-67]. Improvements were also suggested in exercise programs and the age range of the content [61].

Parental feedback was also considered by 2 interventions [61-63].Rheumates@Work, a good-quality study, reported that parents liked the interventions $(63 / 64,99 \%)$ [61] and learned something $(48 / 64,75 \%)$ [61]. Parents also provided high evaluation scores (median 8/10, range 4-10) for ePROfile, reporting ePROfile as useful ( $\mathrm{t} 1=57 / 65,88 \%$; $\mathrm{t} 2=37 / 46,80 \%)$; however, the satisfaction of parents and young people did not differ between IG and CG [62] ([59-63,65-67] Multimedia Appendix 8).

\section{Theme 4: Cost of Delivering the Intervention}

Only 1 of the 7 interventions reported the cost of establishing and maintaining the intervention [61]. Rheumates@Work, a good-quality study, reported on program content $€ 10,000$ (US $\$ 11,888)$; web design, language adaption for young people $€ 1500$ (US \$ 1783); staff numbers ( $n=1-2$ part-time and/or physician/psychologist) for facilitating group sessions; the time needed to monitor the participants' progress and sending emails (30 min/week); and the participants' time (1 hour/week) [61].

Overall, 4 studies reported that they provided participants with a device to enable access to the intervention [59,66,67,69]; 3 fair to good-quality studies supplied a PDA [66,67,69], and 1 fair-quality study provided a wearable accelerometer [59]. All devices were to be returned at the conclusion of the study. Only half of the participants $(15 / 28,55 \%)$ returned the wearable accelerometer [59]. These studies did not report on these costs, and a request for further information was unsuccessful.

\section{Discussion}

\section{Principal Findings}

To the best of our knowledge, this is the first systematic review to evaluate the usability of eHealth and mHealth interventions targeting young people living with JIA (aged 4-18 years). Guided by our 3 research questions, this review identified 7 interventions: Misfit Flash, Rheumates@Work, iPeer2Peer Program, eOuch, ePROfile, SUPER-KIDZ, and Teens taking charge: managing arthritis online. The methodological quality of the studies supporting these interventions ranged from fair $[59,62,63,66,69]$ to good $[60,61,64,65,67,68]$. The dropout rate across 9 studies was low $(49 / 634,7.7 \%$; mean 5, SD 6.1) [59-67].

\section{Identification of the Digital Health Interventions}

\section{Interventions to Improve JIA Model of Care}

Of the interventions, 3 allowed participants to self-report pain [63,66,67,69] or HRQoL [62]. One intervention aimed to generate a computer-based pain summary [63] Another, to improve HRQoL communication during the PR consultation [62]. This form of real-time data collection has the potential to improve data processing [71] and patient monitoring, allowing well-informed, person-centered health care decisions to be made [72].

\section{Interventions to Improve Self-Managing Behavior}

In total, 3 interventions aimed to improve self-management behavior [61,65,68] and 2 interventions aimed to improve physical activity $[59,64,68]$. Participants focused their educational needs on understanding arthritis and disease management issues $[60,61,65]$. Understanding these needs from a young person's perspective is important because there is often a difference in opinion by young people, parents, and health professionals to what self-management programs should include [34]. Research shows that by correctly strengthening a young person's personal knowledge, their motivation and competence to make well-informed health decisions improve [73], reducing their long-term health risks [29].

\section{Usability}

\section{User Engagement}

A range of promotional activities was used to facilitate the engagement of the participants with the interventions. These promotional activities are referred to in the literature as persuasive influences $[74,75]$. Although the studies in this review did not evaluate their effectiveness, notably other systematic reviews have reported their importance [74-76] and supported their inclusion in the intervention design to promote adherence [74]. In fact, for web-based health interventions, a combination should be used, for example, tailored interactive health information, reminders, and incentives to promote active engagement [75], and weekly website updates to increase log-ins [76]. 
The interventions in this review used, on average, 4 persuasive influences (range 1-7), the 2 most common being training [59-63,65] and ongoing human communication [60,61,64-66]. Other studies support the use of human communication through face-to-face segments, peer-to-peer support, a health professional, or counseling to increase website usage [74-76]. In this review, telephone contact was the most common type of human communication. Teens taking charge: managing arthritis online reported how the use of a coach providing telephone support improved website engagement [65]. Interestingly, this study did not employ a health professional, as other systematic reviews have suggested [75,76]. Instead, an undergraduate student studying psychology followed a standardized script to review homework and goals [65], possibly reducing the cost of the intervention.

However, not all forms of human communication identified in this review were supported. A systematic review identified 9 studies where discussion boards only provided a moderate level of peer support for young people [75]. Similarly, Rheumates@Work reported low engagement rates with chat sessions $(17 / 64,27 \%)$ [61], reinforcing the need to include young people in the design and development.

In this review, to improve the young person's experience and ensure that the interventions were achieving the intended interactions, personal barriers were removed [59-61,63-68]. Pain diary reporting times were adjusted according to age, and program schedules were flexible to cater for JIA- and non-JIA-related illnesses [59-61,65], school, and social activities [59-61,65,66]. Technical barriers were also overcome by most interventions that store their data on an external server, rather than the electronic device being used [60-62,65,66]. The privacy of health information was further maintained through secure participant accounts with restricted access [61-63,65,66]. For example, the PR could only see their own patients' results [62]. Similar measures are reflected in other studies, supporting the use of certified servers and data security, despite being costly and requiring a technical team to set up and maintain it $[77,78]$.

\section{User Feedback}

All interventions in this review gained positive feedback from young people [59-63,65-67] and parents [61-63], although some improvements were identified $[60,61,65]$. Rheumates@Work participants, for example, requested more specific exercise programs and age-appropriate content. The targeted age range of 8 to 13 years was too broad-slightly difficult for younger participants, and too childish for older participants [61]. The transparency of the intervention content is also important because the WHO suggests that content needs to align with national guidelines or regulatory statutes; if the intervention is successful, it may be considered as a medical device [41]. Only 4 interventions in this review aligned their content with either guidelines or regulations [61,64], validated tools [62,66,67,69], a research methodology (Delphi technique) [63], and/or learning theory $[61,64]$.

\section{Cost Associated With the Intervention}

Only 1 study in this review reported costs related to the implementation of their intervention [61], despite the WHO strongly suggesting this [48]. Costs should include long-term direct and indirect costs, starting from software development to training, implementation, and the end benefits for patients and the health care system [79]. For example, a recent systematic review of the utilization of mHealth interventions reported reduced travel time and fuel costs for health care workers and patients, and increased working time for health care workers [80]. Considering costs early, during prototype development, may help inform strategic decisions to ensure the intervention, if successful, is cost-effective, easily accessible, and sustainable when translated into the community [79].

\section{Future Research to Consider Gender Differences}

Only 3 studies in this review considered gender differences $[59,60,67]$. This is probably because the JIA population is predominantly female, with 3 to 6.6 females to every 1 male [81]. Although the findings were not significant, gender differences have been reported on internet use by men, women [82], and college students [83]. This indicates the need to include gender differences in future research to identify different support needs and/or gender-specific persuasive influences that could be adopted to promote adherence for young people.

\section{Limitations}

The findings of this systematic review need to be considered cautiously because of the limited number of studies included. Our methodology could have been improved by including qualitative studies in our selection criteria and individually handing searching journals relevant to digital health to ensure no usability issues were omitted and reduce publication bias from the database search.

Meta-analysis was also not possible in this review because all interventions considered different outcomes measures, depending on their stage of development. Instead, this systematic review largely relied on descriptive summaries to organize and clarify the data from formal and informal assessments. This form of analysis can be subjective; participants may have been influenced by the novelty of the intervention, boosting their engagement and feedback. There is also a risk of reporting bias by the author. To reduce this risk and improve transparency, all authors reviewed each stage of the data analysis.

The generalizability of our findings may also be limited. Participants were included in this review with other forms of rheumatic disease, or their diagnosis was unknown or not recorded (86/634, 13.6\%; Table 1) [62,63,66,67]. Dissecting the results for young people, specifically living with JIA, was not possible.

This review also only focused on 3 of our 4 protocol questions: (1) identification of the intervention, (2) usability, and (4) cost, rather than (3) effectiveness, to allow us to capture a more detailed description of the interventions and usability problems faced by participants. The effectiveness of the interventions will be covered in a follow-up publication.

\section{Conclusions}

Using a narrative, descriptive methodology, our review identified 7 interventions for JIA, targeting health issues such as pain, HRQoL, physical activity, and chronic disease 
self-management. The usability of the interventions was facilitated through training and ongoing human communication. Engagement was promoted by a combination of persuasive influences, and barriers preventing adherence were removed through personal reminders and flexible program schedules to cater to JIA- and non-JIA illness or other activities commonly seen in childhood. The feedback obtained was that most young people and their parents liked the interventions. Although too premature to support the effectiveness of our claims, this review will add to the growing body of evidence influencing the development of future eHealth and mHealth interventions. Further research is needed to consider gender differences, associated costs, and the effectiveness of interventions on health outcomes to better support young people living with JIA.

\section{Authors' Contributions}

All authors contributed to the conceptual design, methodology, data extraction, manuscript development, and final manuscript approval.

\section{Conflicts of Interest}

None declared.

\section{Multimedia Appendix 1}

PRISMA (Preferred Reporting Items for Systematic Reviews and Meta-Analyses) checklist.

[DOC File, 63 KB-Multimedia Appendix 1]

\section{Multimedia Appendix 2}

Search terms and database search strategy.

[DOCX File, 119 KB-Multimedia Appendix 2]

\section{Multimedia Appendix 3}

Overview of the seven eHealth and mHealth interventions for JIA.

[DOCX File, 17 KB-Multimedia Appendix 3]

\section{Multimedia Appendix 4}

Overview of the eleven eHealth and mHealth studies targeting Juvenile Idiopathic Arthritis.

[DOCX File , 26 KB-Multimedia Appendix 4]

\section{Multimedia Appendix 5}

Methodological scores of the eleven studies using the Down and Black.

[DOCX File, 16 KB-Multimedia Appendix 5]

\section{Multimedia Appendix 6}

Intervention adherence rates, including week to week, time of day and content adherence by young people with JIA.

[DOCX File, 16 KB-Multimedia Appendix 6]

\section{Multimedia Appendix 7}

Summary of the technical problems experienced by users with JIA, obstructing the adoption of the intervention.

[DOCX File, $14 \mathrm{~KB}$-Multimedia Appendix 7]

\section{Multimedia Appendix 8}

User feedback: Results of Acceptability and Satisfaction questionnaires.

[DOCX File, 17 KB-Multimedia Appendix 8]

\section{References}

1. Juvenile Arthritis. Arthritis Foundation. 2020. URL: https://www.arthritis.org/getmedia/ 73a9f02d-7f91-4084-91c3-0ed0b11c5814/abtn-2020-final.pdf [accessed 2020-11-14]

2. Palman J, Shoop-Worrall S, Hyrich K, McDonagh JE. Update on the epidemiology, risk factors and disease outcomes of Juvenile idiopathic arthritis. Best Pract Res Clin Rheumatol 2018 Apr;32(2):206-222. [doi: 10.1016/j.berh.2018.10.004] [Medline: 30527427] 
3. Thierry S, Fautrel B, Lemelle I, Guillemin F. Prevalence and incidence of juvenile idiopathic arthritis: a systematic review. Joint Bone Spine 2014 Mar;81(2):112-117. [doi: 10.1016/i.jbspin.2013.09.003] [Medline: 24210707]

4. Harrold LR, Salman C, Shoor S, Curtis JR, Asgari MM, Gelfand JM, et al. Incidence and prevalence of juvenile idiopathic arthritis among children in a managed care population, 1996-2009. J Rheumatol 2013 Jul;40(7):1218-1225 [FREE Full text] [doi: 10.3899/jrheum.120661] [Medline: 23588938]

5. Abdwani R, Abdalla E, Al Abrawi S, Al-Zakwani I. Epidemiology of juvenile idiopathic arthritis in Oman. Pediatr Rheumatol Online J 2015 Aug 1;13:33 [FREE Full text] [doi: 10.1186/s12969-015-0030-z] [Medline: 26232056]

6. Juvenile Idiopathic Arthritis. US National Library of Medicine. 2019. URL: https://ghr.nlm.nih.gov/condition/ juvenile-idiopathic-arthritis\#resources [accessed 2019-11-26]

7. Guzman J, Oen K, Huber AM, Watanabe Duffy K, Boire G, Shiff N, ReACCh-Out investigators. The risk and nature of flares in juvenile idiopathic arthritis: results from the reacch-out cohort. Ann Rheum Dis 2016 Jun;75(6):1092-1098. [doi: 10.1136/annrheumdis-2014-207164] [Medline: 25985972]

8. Porth C, Gaspard K. Disorders of the skeletal system, metabolic and rheumatic disorders, juvenile idiopathic arthritis. In: Essentials of Pathophysiology, Concepts of Altered Health States. Fourth Edition. Philadelphia, USA: Wolters Kluwer; 2015:1133-1134.

9. Giancane G, Alongi A, Rosina S, Calandra S, Consolaro A, Ravelli A. Open issues in the assessment and management of pain in juvenile idiopathic arthritis. Clin Exp Rheumatol 2017;35(Suppl 107):123-126 [FREE Full text] [Medline: 28967364]

10. Armbrust W, Siers NE, Lelieveld OT, Mouton LJ, Tuinstra J, Sauer P. Fatigue in patients with juvenile idiopathic arthritis: a systematic review of the literature. Semin Arthritis Rheum 2016 Apr;45(5):587-595. [doi: 10.1016/j.semarthrit.2015.10.008] [Medline: 26656031]

11. What is arthritis? Centers for Disease Control and Prevention. 2020. URL: https://www.cdc.gov/arthritis/basics/childhood. htm [accessed 2020-11-14]

12. Dunkin MA. Is JIA Really an Autoimmune Disease? Arthritis Foundation. 2017. URL: http://www.kidsgetarthritistoo.org/ about-ja/the-basics/ja-autoimmunity.php [accessed 2019-02-01]

13. Haverman L, Grootenhuis MA, van den Berg JM, van Veenendaal M, Dolman KM, Swart JF, et al. Predictors of health-related quality of life in children and adolescents with juvenile idiopathic arthritis: results from a Web-based survey. Arthritis Care Res (Hoboken) 2012 May;64(5):694-703 [FREE Full text] [doi: 10.1002/acr.21609] [Medline: 22238240]

14. Stinson JN, Hayden JA, Ahola Kohut S, Soobiah C, Cartwright J, Weiss SK, et al. Sleep problems and associated factors in children with juvenile idiopathic arthritis: a systematic review. Pediatr Rheumatol Online J 2014;12:19 [FREE Full text] [doi: 10.1186/1546-0096-12-19] [Medline: 24940168]

15. Bouaddi I, Rostom S, El Badri D, Hassani A, Chkirate B, Amine B, et al. Impact of juvenile idiopathic arthritis on schooling. BMC Pediatr 2013 Jan 7;13:2 [FREE Full text] [doi: 10.1186/1471-2431-13-2] [Medline: 23289498]

16. Díaz-Mendoza AC, Modesto Caballero C, Navarro-Cendejas J. Analysis of employment rate and social status in young adults with childhood-onset rheumatic disease in Catalonia. Pediatr Rheumatol Online J 2015 Jul 11;13:29 [FREE Full text] [doi: 10.1186/s12969-015-0026-8] [Medline: 26162373]

17. Rashid A, Cordingley L, Carrasco R, Foster HE, Baildam EM, Chieng A, et al. Patterns of pain over time among children with juvenile idiopathic arthritis. Arch Dis Child 2018 May;103(5):437-443 [FREE Full text] [doi: 10.1136/archdischild-2017-313337] [Medline: 29175824]

18. Moorthy LN, Peterson MG, Hassett AL, Lehman TJ. Burden of childhood-onset arthritis. Pediatr Rheumatol Online J 2010 Jul 8;8:20 [FREE Full text] [doi: 10.1186/1546-0096-8-20] [Medline: 20615240]

19. Model of Care for the NSW Paediatric Rheumatology Network. Agency for Clinical Innovation. 2013. URL: https://www. aci.health.nsw.gov.au/ data/assets/pdf file/0011/183656/HS13-027 ACI PaedRheum web.pdf [accessed 2020-11-14]

20. Cox A, Piper S, Singh-Grewal D. Pediatric rheumatology consultant workforce in Australia and New Zealand: the current state of play and challenges for the future. Int J Rheum Dis 2017 May;20(5):647-653. [doi: 10.1111/1756-185X.12802] [Medline: 26864133]

21. Foster H, Rapley T. Access to pediatric rheumatology care -- a major challenge to improving outcome in juvenile idiopathic arthritis. J Rheumatol 2010 Nov;37(11):2199-2202. [doi: 10.3899/jrheum.100910] [Medline: 21041261]

22. Al Maini M, Adelowo F, Al Saleh J, Al Weshahi Y, Burmester G, Cutolo M, et al. The global challenges and opportunities in the practice of rheumatology: white paper by the World Forum on Rheumatic and Musculoskeletal Diseases. Clin Rheumatol 2015 May;34(5):819-829 [FREE Full text] [doi: 10.1007/s10067-014-2841-6] [Medline: 25501633]

23. Khawaja K, Al-Maini M. Access to pediatric rheumatology care for juvenile idiopathic arthritis in the United Arab Emirates. Pediatr Rheumatol Online J 2017 May 16;15(1):41 [FREE Full text] [doi: 10.1186/s12969-017-0170-4] [Medline: 28511684]

24. Ooi PL, Shek LP. Paediatric rheumatology: a subspecialty in its infancy that is making leaps and bounds. Singapore Med J 2014 May;55(5):242-243 [FREE Full text] [doi: 10.11622/smedj.2014074] [Medline: 24862745]

25. Spencer C. Why should pediatric rheumatology be recognized as a separate subspecialty: an open letter to medical councils and government agencies. Pediatr Rheumatol Online J 2007 Nov 21;5:21. [doi: 10.1186/1546-0096-5-21] [Medline: $\underline{18031581]}$ 
26. Tong A, Jones J, Speerin R, Filocamo K, Chaitow J, Singh-Grewal D. Consumer perspectives on pediatric rheumatology care and service delivery: a qualitative study. J Clin Rheumatol 2013 Aug;19(5):234-240. [doi: 10.1097/RHU.0b013e31829d4e82] [Medline: 23872547]

27. van Dijkhuizen EH, Egert T, Egert Y, Costello W, Schoemaker C, Fernhout M, et al. Patient's experiences with the care for juvenile idiopathic arthritis across Europe. Pediatr Rheumatol Online J 2018 Feb 8;16(1):10 [FREE Full text] [doi: 10.1186/s12969-018-0226-0] [Medline: 29422094]

28. Coda A, Jones J, Grech D, Grewal DS. Survey of parent and carer experiences and expectations of paediatric rheumatology care in New South Wales. Aust Health Rev 2017 Aug;41(4):372-377. [doi: 10.1071/AH16061] [Medline: 27467400]

29. Sawyer SM, Afifi RA, Bearinger LH, Blakemore S, Dick B, Ezeh AC, et al. Adolescence: a foundation for future health. Lancet 2012 Apr 28;379(9826):1630-1640. [doi: 10.1016/S0140-6736(12)60072-5] [Medline: 22538178]

30. Munro J, Murray K, Boros C, Chaitow J, Allen RC, Akikusa J, Australian Paediatric Rheumatology Group. Australian paediatric rheumatology group standards of care for the management of juvenile idiopathic arthritis. J Paediatr Child Health 2014 Sep;50(9):663-666. [doi: 10.1111/jpc.12462] [Medline: 25156704]

31. Sawyer SM, Aroni RA. Self-management in adolescents with chronic illness. What does it mean and how can it be achieved? Med J Aust 2005 Oct 17;183(8):405-409. [Medline: 16225444]

32. Sawyer S. Asthma in young people. In: Silverman M, editor. Childhood Asthma and Other Wheezing Disorders. Second Edition. New York, USA: Oxford University Press; 2002:351-358.

33. Beacham BL, Deatrick JA. Children with chronic conditions: perspectives on condition management. J Pediatr Nurs 2015;30(1):25-35 [FREE Full text] [doi: 10.1016/j.pedn.2014.10.011] [Medline: 25458105]

34. Waite-Jones JM, Majeed-Ariss R, Smith J, Stones SR, van Rooyen V, Swallow V. Young people's, parents', and professionals' views on required components of mobile apps to support self-management of juvenile arthritis: qualitative study. JMIR Mhealth Uhealth 2018 Jan 19;6(1):e25 [FREE Full text] [doi: 10.2196/mhealth.9179] [Medline: 29351898]

35. Meskó B, Drobni Z, Bényei E, Gergely B, Győrffy Z. Digital health is a cultural transformation of traditional healthcare. Mhealth 2017;3:38 [FREE Full text] [doi: 10.21037/mhealth.2017.08.07] [Medline: 29184890]

36. Sendra S, Parra L, Lloret J, Tomás J. Smart system for children's chronic illness monitoring. Inform Fusion 2018 Mar;40:76-86 [FREE Full text] [doi: 10.1016/j.inffus.2017.06.002]

37. Individuals Using the Internet (\% of Population). International Telecommunication Union, World Telecommunication/ICT Development Report and Database. 2019. URL: https://data.worldbank.org/indicator/IT.NET.USER.ZS [accessed 2020-11-14]

38. The Australian Cut. Deloitte's Technology Media Telecommunications (TMT) Industry Group. 2017. URL: https://www2. deloitte.com/au/mobile-consumer-survey-2017 [accessed 2018-12-10]

39. Cohen SB, Grote KD, Pietraszek WE, Laflamme F. Increasing consumerism in healthcare through intelligent information technology. Am J Manag Care 2010 Dec;16(12 Suppl HIT):SP37-SP43 [FREE Full text] [Medline: 21314219]

40. Hesse BW, Shneiderman B. eHealth research from the user's perspective. Am J Prev Med 2007 May;32(5 Suppl):S97-103 [FREE Full text] [doi: 10.1016/j.amepre.2007.01.019] [Medline: 17466825]

41. Agarwal S, LeFevre AE, Lee J, L'Engle K, Mehl G, Sinha C, WHO mHealth Technical Evidence Review Group. Guidelines for reporting of health interventions using mobile phones: mobile health (mHealth) evidence reporting and assessment (mERA) checklist. Br Med J 2016 Mar 17;352:i1174. [doi: 10.1136/bmj.i1174] [Medline: 26988021]

42. Law E, Abrahão S. Interplay between User Experience (UX) evaluation and system development. Int J Hum Comput Stud 2014 Jun;72(6):523-525. [doi: 10.1016/j.ijhcs.2014.03.003]

43. Barnum CM. Usability Testing Essentials: Ready, Set...Test!. In: Kaufmann M, editor. Usability Testing Essentials. Elsevier, BV: Science Direct; 2011:53-81.

44. Nikolaus S, Bode C, Taal E, Vonkeman HE, Glas CA, van de Laar MA. Acceptance of new technology: a usability test of a computerized adaptive test for fatigue in rheumatoid arthritis. JMIR Hum Factors 2014 Dec 4;1(1):e4 [FREE Full text] [doi: 10.2196/humanfactors.3424] [Medline: 27025404]

45. Alwashmi MF, Hawboldt J, Davis E, Fetters MD. The iterative convergent design for mobile health usability testing: mixed methods approach. JMIR Mhealth Uhealth 2019 Apr 26;7(4):e11656 [FREE Full text] [doi: 10.2196/11656] [Medline: 31025951]

46. Third A, Bellerose D, Diniz DO, Lala G. Young and Online: Children's Perspectives on Life in the Digital Age. Western Sydney University. 2017. URL: https://apo.org.au/sites/default/files/resource-files/2017-12/apo-nid139346.pdf [accessed 2020-02-10]

47. Craig P, Dieppe P, Macintyre S, Michie S, Nazareth I, Petticrew M. Developing and Evaluating Complex Interventions: Following Considerable Development in the Field Since 2006, MRC and NIHR Have Jointly Commissioned an Update of This Guidance to Be Published in 2019. Medical Research Council. URL: https://mrc.ukri.org/documents/pdf/ complex-interventions-guidance [accessed 2020-03-05]

48. Monitoring and Evaluating Digital Health Interventions: a Practical Guide to Conducting Research and Assessment. World Health Organization. 2016. URL: https://www.who.int/reproductivehealth/publications/mhealth/digital-health-interventions/ en/ [accessed 2018-12-10] 
49. Moher D, Liberati A, Tetzlaff J, Altman DG, PRISMA Group. Preferred reporting items for systematic reviews and meta-analyses: the PRISMA statement. Br Med J 2009 Jul 21;339:b2535 [FREE Full text] [doi: 10.1136/bmj.b2535] [Medline: 19622551]

50. Butler S, Sculley D, Fellas A, Santos D, Singh-Grewal D, Girones X, et al. Ehealth and Mhealth Interventions Supporting Children and Adolescents Living With Juvenile Idiopathic Arthritis (JIA): a Systematic Review. National Institute for Health Research. 2019. URL: https://www.crd.york.ac.uk/prospero/display record.php?RecordID=108985 [accessed 2019-08-04]

51. Petty RE, Southwood TR, Manners P, Baum J, Glass DN, Goldenberg J, International League of Associations for Rheumatology. International league of associations for rheumatology classification of juvenile idiopathic arthritis: second revision, Edmonton, 2001. J Rheumatol 2004 Feb;31(2):390-392. [Medline: 14760812]

52. Mhealth: New Horizons for Health Through Mobile Technologies. World Health Organization. 2011. URL: https://www. who.int/goe/publications/goe mhealth web.pdf [accessed 2019-08-04]

53. Better Systematic Review Management. Covidence. 2018. URL: https://www.covidence.org/home [accessed 2018-12-10]

54. Downs SH, Black N. The feasibility of creating a checklist for the assessment of the methodological quality both of randomised and non-randomised studies of health care interventions. J Epidemiol Community Health 1998 Jun;52(6):377-384 [FREE Full text] [doi: 10.1136/jech.52.6.377] [Medline: 9764259]

55. Quality Checklist for Health Care Intervention Studies. National Collaborating Centre for Methods and Tools. URL: https:/ /www.nccmt.ca/knowledge-repositories/search/9 [accessed 2019-02-25]

56. O'Connor SR, Tully MA, Ryan B, Bradley JM, Baxter GD, McDonough SM. Failure of a numerical quality assessment scale to identify potential risk of bias in a systematic review: a comparison study. BMC Res Notes 2015 Jun 6;8:224 [FREE Full text] [doi: 10.1186/s13104-015-1181-1] [Medline: 26048813]

57. Ryan R. Data Synthesis and Analysis. Cochrane Consumers and Communication Review Group. 2013. URL: https://cccrg. cochrane.org/sites/cccrg.cochrane.org/files/public/uploads/Analysis.pdf [accessed 2019-10-02]

58. Popay J, Robert H, Sowden A, Petticrew M, Arai L. Guidance on the Conduct of Narrative Synthesis in Systematic Reviews: a Product From the ESRC Methods Programme. Lancaster University. 2006. URL: http://citeseerx.ist.psu.edu/viewdoc/ download?doi=10.1.1.178.3100\&rep=rep1\&type=pdf [accessed 2018-12-10]

59. Heale LD, Dover S, Goh YI, Maksymiuk VA, Wells GD, Feldman BM. A wearable activity tracker intervention for promoting physical activity in adolescents with juvenile idiopathic arthritis: a pilot study. Pediatr Rheumatol Online J 2018 Oct 22;16(1):66 [FREE Full text] [doi: 10.1186/s12969-018-0282-5] [Medline: 30348203]

60. Stinson J, Ahola Kohut S, Forgeron P, Amaria K, Bell M, Kaufman M, et al. The iPeer2Peer program: a pilot randomized controlled trial in adolescents with juvenile idiopathic arthritis. Pediatr Rheumatol Online J 2016 Sep 2;14(1):48 [FREE Full text] [doi: 10.1186/s12969-016-0108-2] [Medline: 27590668]

61. Armbrust W, Bos JJ, Cappon J, van Rossum MA, Sauer PJJ, Wulffraat N, et al. Design and acceptance of Rheumates@Work, a combined internet-based and in person instruction model, an interactive, educational, and cognitive behavioral program for children with juvenile idiopathic arthritis. Pediatr Rheumatol Online J 2015 Jul 23;13:31 [FREE Full text] [doi: 10.1186/s12969-015-0029-5] [Medline: 26202161]

62. Haverman L, van Rossum MA, van Veenendaal M, van den Berg JM, Dolman KM, Swart J, et al. Effectiveness of a web-based application to monitor health-related quality of life. Pediatrics 2013 Feb;131(2):e533-e543. [doi: 10.1542/peds.2012-0958] [Medline: 23296436]

63. Stinson JN, Connelly M, Jibb LA, Schanberg LE, Walco G, Spiegel LR, et al. Developing a standardized approach to the assessment of pain in children and youth presenting to pediatric rheumatology providers: a Delphi survey and consensus conference process followed by feasibility testing. Pediatr Rheumatol Online J 2012 Apr 10;10(1):7 [FREE Full text] [doi: 10.1186/1546-0096-10-7] [Medline: 22490427]

64. Lelieveld OT, Armbrust W, Geertzen JH, de Graaf I, van Leeuwen MA, Sauer PJ, et al. Promoting physical activity in children with juvenile idiopathic arthritis through an internet-based program: results of a pilot randomized controlled trial. Arthritis Care Res (Hoboken) 2010 May;62(5):697-703 [FREE Full text] [doi: 10.1002/acr.20085] [Medline: 20191468]

65. Stinson JN, McGrath PJ, Hodnett ED, Feldman BM, Duffy CM, Huber AM, et al. An internet-based self-management program with telephone support for adolescents with arthritis: a pilot randomized controlled trial. J Rheumatol 2010 Sep;37(9):1944-1952. [doi: 10.3899/jrheum.091327] [Medline: 20595280]

66. Stinson JN, Petroz GC, Stevens BJ, Feldman BM, Streiner D, McGrath PJ, et al. Working out the kinks: testing the feasibility of an electronic pain diary for adolescents with arthritis. Pain Res Manag 2008;13(5):375-382 [FREE Full text] [doi: 10.1155/2008/326389] [Medline: 18958308 ]

67. Stinson JN, Stevens BJ, Feldman BM, Streiner D, McGrath PJ, Dupuis A, et al. Construct validity of a multidimensional electronic pain diary for adolescents with arthritis. Pain 2008 Jun;136(3):281-292. [doi: 10.1016/j.pain.2007.07.002] [Medline: 17723279$]$

68. Armbrust W, Bos GJ, Wulffraat NM, van Brussel M, Cappon J, Dijkstra PU, et al. Internet program for physical activity and exercise capacity in children with juvenile idiopathic arthritis: a multicenter randomized controlled trial. Arthritis Care Res (Hoboken) 2017 Jul;69(7):1040-1049 [FREE Full text] [doi: 10.1002/acr.23100] [Medline: 27696793] 
69. Stinson JN, Jibb LA, Lalloo C, Feldman BM, McGrath PJ, Petroz GC, et al. Comparison of average weekly pain using recalled paper and momentary assessment electronic diary reports in children with arthritis. Clin J Pain 2014 Dec;30(12):1044-1050. [doi: 10.1097/AJP.0000000000000072] [Medline: 24535055]

70. Cleeland CS. Breif Pain Inventory - Short form. University of Texas. 2003. URL: http://www.npcrc.org/files/news/ briefpain short.pdf [accessed 2019-04-10]

71. Fernandes CO, de Lucena CJ. An internet of things application with an accessible interface for remote monitoring patients. In: Marcus A, editor. User Experience, and Usability: Interactive Experience Design, DUXU 2015, Lecture Notes in Computer Science, 9188. Cham, UK: Springer; 2015.

72. WHO Global Strategy on People-centred and Integrated Health Services: Interim Report. World Health Organization. 2016. URL: https://apps.who.int/iris/bitstream/handle/10665/155002/WHO_HIS_SDS_2015.6_eng.pdf [accessed 2020-05-02]

73. Bröder J, Okan O, Bauer U, Bruland D, Schlupp S, Bollweg TM, et al. Health literacy in childhood and youth: a systematic review of definitions and models. BMC Public Health 2017 Apr 26;17(1):361 [FREE Full text] [doi: 10.1186/s12889-017-4267-y] [Medline: 28441934]

74. Kelders SM, Kok RN, Ossebaard HC, Van Gemert-Pijnen J. Persuasive system design does matter: a systematic review of adherence to web-based interventions. J Med Internet Res 2012 Nov 14;14(6):e152 [FREE Full text] [doi: 10.2196/jmir.2104] [Medline: 23151820]

75. Crutzen R, de Nooijer J, Brouwer W, Oenema A, Brug J, de Vries NK. Strategies to facilitate exposure to internet-delivered health behavior change interventions aimed at adolescents or young adults: a systematic review. Health Educ Behav 2011 Feb;38(1):49-62. [doi: 10.1177/1090198110372878] [Medline: 21189422]

76. Brouwer W, Kroeze W, Crutzen R, de Nooijer J, de Vries NK, Brug J, et al. Which intervention characteristics are related to more exposure to internet-delivered healthy lifestyle promotion interventions? A systematic review. J Med Internet Res 2011 Jan 6;13(1):e2 [FREE Full text] [doi: 10.2196/jmir.1639] [Medline: 21212045]

77. Müthing J, Brüngel R, Friedrich CM. Server-focused security assessment of mobile health apps for popular mobile platforms. J Med Internet Res 2019 Jan 23;21(1):e9818 [FREE Full text] [doi: 10.2196/jmir.9818] [Medline: $\underline{30672738]}$

78. Spigel L, Wambugu S, Villella C. Mhealth Data Security, Privacy, and Confidentiality: Guidelines for Program Implementers and Policymakers. MEASURE Evaluation. 2018. URL: https://www.measureevaluation.org/resources/publications/ ms-17-125a [accessed 2020-11-17]

79. The MAPS Toolkit: Mhealth Assessment and Planning for Scale. World Health Organization. 2015. URL: https://apps. who.int/iris/handle/10665/185238 [accessed 2018-12-10]

80. White A, Thomas DS, Ezeanochie N, Bull S. Health worker mhealth utilization: a systematic review. Comput Inform Nurs 2016 May;34(5):206-213 [FREE Full text] [doi: 10.1097/CIN.0000000000000231] [Medline: 26955009]

81. Cattalini M, Soliani M, Caparello MC, Cimaz R. Sex differences in pediatric rheumatology. Clin Rev Allergy Immunol 2019 Jun;56(3):293-307. [doi: 10.1007/s12016-017-8642-3] [Medline: 28849549]

82. Bidmon S, Terlutter R. Gender differences in searching for health information on the internet and the virtual patient-physician relationship in Germany: exploratory results on how men and women differ and why. J Med Internet Res 2015 Jun 22;17(6):e156 [FREE Full text] [doi: 10.2196/jmir.4127] [Medline: 26099325]

83. Hu T, Zhang X, Dai H, Zhang P. An examination of gender differences among college students in their usage perceptions of the internet. Educ Inf Technol 2011 Apr 13;17(3):315-330 [FREE Full text] [doi: 10.1007/s10639-011-9160-1]

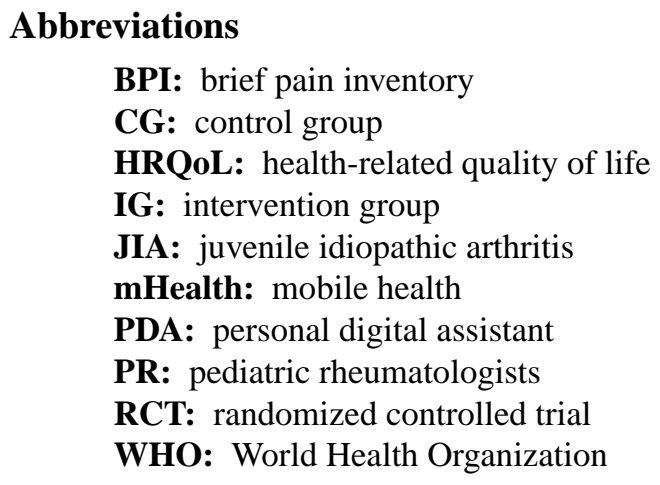


Edited by G Eysenbach; submitted 11.08.19; peer-reviewed by D Leightley, A Wickersham; comments to author 14.10.19; revised version received 27.01.20; accepted 03.10.20; published 01.12.20

Please cite as:

Butler S, Sculley D, Santos DS, Fellas A, Gironès X, Singh-Grewal D, Coda A

Usability of eHealth and Mobile Health Interventions by Young People Living With Juvenile Idiopathic Arthritis: Systematic Review JMIR Pediatr Parent 2020;3(2):e15833

URL: http://pediatrics.jmir.org/2020/2/e15833/

doi: $10.2196 / 15833$

PMID: $\underline{3258786}$

(CSonia Butler, Dean Sculley, Derek Santos Santos, Antoni Fellas, Xavier Gironès, Davinder Singh-Grewal, Andrea Coda. Originally published in JMIR Pediatrics and Parenting (http://pediatrics.jmir.org), 01.12.2020. This is an open-access article distributed under the terms of the Creative Commons Attribution License (https://creativecommons.org/licenses/by/4.0/), which permits unrestricted use, distribution, and reproduction in any medium, provided the original work, first published in JMIR Pediatrics and Parenting, is properly cited. The complete bibliographic information, a link to the original publication on http://pediatrics.jmir.org, as well as this copyright and license information must be included. 